\title{
Physical Activity and Health-Promoting Lifestyle of Student Nurses in Malaysia
}

\author{
Soh Kim Geok ${ }^{*}$, Aminuddin Yusof', Soh Kim Lam², Salimah Japar², Ong Swee Leong3, \\ Mohd. Sofian Omar Fauzee ${ }^{4}$ \\ ${ }^{1}$ Department of Sport Studies, Faculty of Educational Studies/Sport Academy, University Putra Malaysia, \\ Serdang, Malaysia \\ ${ }^{2}$ Nursing Unit, Department of Medicine, Faculty of Medicine and Health Science, University Putra Malaysia, \\ Serdang, Malaysia \\ ${ }^{3}$ Nursing Department, Faculty of Medicine and Health Sciences, University Sultan Zainal Abidin, Terengganu, \\ Malaysia \\ ${ }^{4}$ School of Education and Modern Languages, College of Art and Sciences, University Utara Malaysia, Sintok, \\ Malaysia \\ Email: ${ }^{*}$ kims@upm.edu.my, ${ }^{*}$ kimgeoks@yahoo.com
}

Received December 2014

\section{Abstract}

Studies have indicated that lack of regular physical exercise and not adhering to a health-promoting lifestyle among student nurses are barriers to their encouraging patients to exercise. On the other hand, nurses who personally embrace physical activity are more likely to encourage their patients to improve their health through physical activity or diet. As a result, promoting an active and healthy lifestyle among student nurses is important because this has a crucial role in their subsequently encouraging healthy lifestyles among their patients. The aims of this study were to determine the physical activity levels and health-promoting lifestyles among student nurses in Malaysia, and to investigate whether there was a correlation between the physical activity levels of student nurses and their lifestyle habits. Further investigation was also carried out to correlate lifestyle habits with physical activity during weekdays and at the weekends. This study involved 189 student nurses who were pursuing Diplomas and Bachelor Degrees in local government universities. The Yamax Digi-Walker pedometer was used to measure physical activity, while the Health-Promoting Lifestyle Profile (HPLP) II questionnaire was used to assess the health-promoting lifestyles of the participants. The HPLP II consisted of six sub-scales which included health responsibility, physical activity, nutrition, spiritual growth, interpersonal relations, and stress management. According to the results on physical activity, the student nurses had a mean of 8275.97 \pm 2210.174 steps per day and were thus categorised as somewhat active. Additionally, the student nurses were found to be more active during weekends $(M=8389.75, S D=2689.12)$ as compared to weekdays $(M=8230.46, S D=2353.97)$. According to previous studies, both step counts are classified in the "somewhat active" category. Overall, the results for HPLP II showed that student nurses students in Malaysia had a positive health-promoting lifestyle with a score of $2.58 \pm 0.34$ on a 4-point Likert scale. The highest score was reported in spiritual growth, with a score of $2.92 \pm 0.43$. Meanwhile, physical activity was observed to be the lowest, with a score of

*Corresponding author.

How to cite this paper: Geok, S.K., Yusof, A., Lam, S.K., Japar, S., Leong, O.S. and Fauzee, Mohd.S.O. (2015) Physical Activity and Health-Promoting Lifestyle of Student Nurses in Malaysia. Journal of Biosciences and Medicines, 3, 78-87. 
$1.74 \pm 0.39$. The results found no correlation between physical activity and overall health-promoting lifestyle among student nurses in Malaysia $(r=0.06, n=189, p<0.37)$. However, there was a significant relationship between physical activity (measured by the pedometer) and physical activity habit (measured through the questionnaire) among the student nurses $(r=0.24, n=189, p<$ 0.01). According to the findings, when the participants indicated in the questionnaire that they were active physically, the pedometer readings also showed a corresponding similarity in terms of their daily physical activities.

\section{Keywords}

Physical Activity, Health-Promotion Lifestyle, Nursing Students, Pedometer

\section{Introduction}

Malaysia is a fast-developing, multicultural country. In the process of striving to achieve a developed nation status by 2020, its citizens need to be more aware of the importance of adopting healthy lifestyles in order to cope with the challenges of modern living. Formerly an agricultural country, the Malaysian economy is now increasingly being sustained by industries. The workforce, which used to be labour-intensive, is now being replaced by machines. Previously, healthcare efforts in Malaysia have been directed towards combating communicable diseases such as pneumonia and tuberculosis. However, the focus is now on combating non-communicable diseases such as heart diseases, cancer, and diabetes. All these diseases are very much associated with the changing lifestyles of Malaysians. The National Morbidity Survey reported that in 2009, two out of five Malaysian adults were obese [1]. This alarming fact has prompted the Malaysian government to introduce many programs to promote healthier lifestyles, and especially to be physically more active. Among the programs are the 10,000 Steps Program initiated by the Ministry of Health in July 2009 [1], and Malaysia Cergas or A Fit Malaysia in 1985. However, owing to the lack of studies on these initiatives, there is insufficient evidence to determine the effectiveness of these programs. Nevertheless, what is clear is that the increasing number of obese Malaysians and patients with heart diseases, cancer, and diabetes indicate that these initiatives have largely failed to achieve their objectives.

Nurses play an important role in influencing members of the public to maintain good health by adopting healthy lifestyles. In Malaysia, nurses are the main players in providing and performing health promotion initiatives. They are often sought by not only their own patients but also members of the community to advise on matters related to health. Hence it is important that nurses themselves walk the talk, so to speak. Studies indicate that lack of regular physical exercise among student nurses is a barrier to their encouraging patients to be more active physically [2].

In Malaysia, many institutions of higher learning, as well as the Ministry of Health, provide training to ensure that there is a well-educated and empathetic nursing workforce. However, studies that examine the level of physical activity and health-promoting lifestyle of nurses are scarce. Moreover, it is very difficult, if at all possible, to ascertain whether the current nursing education programs implemented in Malaysia encourage nurses to be physically active and to maintain a healthy lifestyle. Studies need to be carried out to provide information on fundamentals regarding the physical activity levels and lifestyle habits among Malaysian nurses. In depth information related to physical activity levels such as the daily walking distance and calories burnt by nurses would provide better insight on the lifestyle of nurses. It is vital that nurses maintain a healthy routine to help prevent excessive weight gain that can lead to non-communicable diseases such as hypertension, coronary heart dieses, diabetes, stroke, and cancer among adults [3] [4]. Furthermore, studies also show that when a practitioner has personally embraced physical activity as a daily routine, he or she is more likely to encourage patients to do likewise to improve their health [5] [6]. Hence, this study was aimed at determining the level of physical activity and lifestyle habit among nursing students in Malaysia, focusing on whether there was a correlation between physical activity levels and lifestyle habits among student nurses. A further investigation was also carried out to correlate lifestyle habit with the level of physical activity during weekdays, as compared with that on weekends. 


\section{Materials and Methods}

\subsection{Participants}

One hundred and eighty nine (189) from three universities in Malaysia, viz. Universiti Malaya (UM), Universiti Putra Malaysia (UPM), and Universiti Sultan Zainal Abidin (UniSZA), were selected to participate in this research. One hundred nurses were attending diploma courses in these universities, while the rest were pursuing bachelor degree courses. This study focused only on female student nurses who were in their second and third years. This was to ensure that the selected student nurses had acquired adequate knowledge on health matters and had had some training in the nursing field before participating in this study. Prior to the research, approvable was obtained from the university authorities. The mean age of these nurses was 20.76, with SD $=3.73$. Table 1 shows the physical profile of the nursing students, such as age, height, body mass, and body mass index (BMI):

\subsection{Instrumentation}

1) Physical Activity Measurement

The Yamex-Digi Walker CW700 pedometer, used to measure the subjects' physical activity, was chosen because it was able to accurately measure slow to moderate walking steps [7]; it could also provide information on the daily distance covered and calculate the calories burnt. The sealed pedometer was worn daily by the participants (except during sleep and bathing) for seven consecutive days. These seven days consisted of five working days and weekends. According to [8] and [9], step counts taken for at least three days are sufficient because they are highly correlated with the subject's physical activity levels [10]. If little walking was done on any day ( $\leq 2500$ steps), the subjects were required to fill out the Daily Activity to explain the reason for this result. This was done to ensure that the low count was not a mistake. If the pedometer had not been worn, the recording would be extended another day, depending on the day that the participant forgot to wear the pedometer. The Daily Activity Form acted as a reminder to the participant to wear the pedometer, especially as the subjects' activity recording had to be taken hourly.

2) Health-Promoting Lifestyle Measurement

The Health-Promoting Lifestyle Profile (HPLP) II questionnaire developed by Walker in 1987 was used with the author's permission to evaluate the lifestyle habit of the student nurses [11]. The HPLP II questionnaire had six subscales, viz. Health Responsibility, Physical Activity, Nutrition, Spiritual Growth, Interpersonal Relations, and Stress Management. The participants were required to answer all the 52 questions in the questionnaire which contained statements about the nurse's present lifestyle and personal habits. The lifestyle habit was measured using a four-point Likert scale. For each measured behavior, the participants indicated the frequency with which they had engaged in it by circling their selected answer from the scales provided such as: never, sometimes, often, and routinely.

\subsection{Statistical Analysis}

Descriptive statistics such as minimum value, maximum value, mean, and percentage were used to describe the step counts and lifestyle habit among the participants. In addition, a correlation test was used to determine whether the physical activity level and health-promoting lifestyle among these nurses were closely related. The statistical significance was set at alpha $=0.05$.

\section{Results}

The first part of the study collected detailed descriptive information on the level of physical activity and healthpromoting lifestyle across different subscales, and the amount of calories consumed by the student nurses during the week. Table 2 shows the results obtained from the preliminary analysis of the data:

Table 1. Physical profile among nurses in Malaysia.

\begin{tabular}{|c|c|c|c|c|}
\hline Physical Profile $(\mathrm{N}=189)$ & Minimum & Maximum & Mean & SD \\
\hline Age & 19.00 & 40.00 & 20.76 & 3.73 \\
\hline Height & 141.00 & 174.00 & 156.21 & 5.42 \\
\hline Body Mass & 34.00 & 92.00 & 52.92 & 10.36 \\
\hline Body Mass Index & 15.00 & 34.00 & 21.61 & 3.77 \\
\hline
\end{tabular}


As seen from the data in Table 2, the nursing students walked less on a weekday than Saturday or Sunday. The mean step reported during the weekday $(8230.46 \pm 2353.97)$ was lower as compared to the mean step during the weekend which was $8389.75 \pm 2689.12$. Table 3 also shows the distance that student nurses walked during weekdays and weekends.

As shown in Table 3, the lower step counts also translated into lower walking distance and calories burnt during the weekday as compared to the weekend. According to the results, the mean walking distance during weekday was $5.24 \pm 1.54 \mathrm{~km}$ as compared to the mean walking distance during weekend, which was $5.34 \pm 1.71$ $\mathrm{km}$. The participants also reported lower calories burnt during the weekday i.e. $247.48 \pm 94.97$ calories as compared to $252.38 \pm 102.4$ calories during the weekend. Detail analysis using t-test showed that there was a significant different between number of step counts during weekday as compared to weekend.

This study also examined health-promoting lifestyles of student nurses in Malaysia. The results are shown in Table 4.

Table 2. Physical activity result of student nurses in Malaysia ( $\mathrm{N}=189)$.

\begin{tabular}{ccccc}
\hline Day & Minimum & Maximum & Mean & SD \\
\hline Monday & 1486.00 & 17956.00 & 8801.84 & 3526.42 \\
Tuesday & 2257.00 & 19067.00 & 8047.51 & 3331.32 \\
Wednesday & 2183.00 & 17099.00 & 8161.07 & 3347.81 \\
Thursday & 1219.00 & 24057.00 & 8129.62 & 3224.84 \\
Friday & 1649.00 & 23810.00 & 8502.46 & 3792.16 \\
Total Steps (weekday) & 14864.00 & 81492.00 & 41152.29 & 11769.82 \\
Mean Steps per weekday & 2972.80 & 16298.40 & 8230.46 & 2353.97 \\
Saturday & 1129.00 & 16941.00 & 7533.53 & 3140.41 \\
Sunday & 1719.00 & 16951.00 & 8752.02 & 3047.48 \\
Total Steps (weekend) & 5628.00 & 31354.00 & 16779.49 & 5378.24 \\
Mean Steps per day (weekend) & 2814.00 & 15677.00 & 8389.75 & 2689.12 \\
Total Steps (7 Days) & 24768.00 & 107467.00 & 57928.05 & 15470.72 \\
Mean Steps per day (over 7 Days) & 3538.29 & 15352.43 & 8275.97 & 2210.17 \\
\hline
\end{tabular}

Table 3. Daily walking distance and calories burnt by Malaysian student nurses ( $\mathrm{N}=189)$

\begin{tabular}{cccccccccc}
\hline & $\mathbf{D}^{*}$ & \multicolumn{1}{c}{$\mathbf{C}$} & $\mathbf{D}$ & $\mathbf{C}$ & $\mathbf{D}$ & $\mathbf{C}$ & $\mathbf{D}$ & $\mathbf{C}$ \\
\cline { 2 - 9 } & \multicolumn{2}{c}{ Min } & \multicolumn{2}{c}{ Max } & Mean & SD & Mean & SD \\
\hline Monday & 0.90 & 31.30 & 11.82 & 926.50 & 5.60 & 269.90 & 2.28 & 138.60 \\
Tuesday & 1.26 & 24.30 & 11.35 & 715.50 & 5.11 & 241.74 & 2.08 & 123.31 \\
Wednesday & 1.37 & 62.80 & 10.97 & 621.00 & 5.19 & 244.25 & 2.12 & 119.61 \\
Thursday & 0.68 & 30.00 & 11.25 & 714.90 & 4.78 & 240.17 & 1.98 & 112.17 \\
Friday & 1.00 & 42.20 & 18.57 & 852.30 & 5.11 & 241.32 & 2.30 & 124.80 \\
${ }^{*}$ Total (weekday) & 8.30 & 373.60 & 63.54 & 2932.90 & 26.23 & 1237.40 & 7.70 & 474.88 \\
${ }^{*}$ Mean (per weekday) & 1.66 & 74.72 & 12.71 & 586.58 & 5.24 & 247.48 & 1.54 & 94.97 \\
Saturday & 0.69 & 27.70 & 11.25 & 836.20 & 4.78 & 227.43 & 1.98 & 115.02 \\
Sunday & 1.68 & 63.70 & 12.25 & 841.40 & 5.90 & 277.33 & 2.14 & 118.29 \\
${ }^{*}$ Total (weekend) & 3.81 & 122.60 & 20.66 & 1528.50 & 10.69 & 504.76 & 3.43 & 204.87 \\
${ }^{*}$ Mean per day (weekend) & 1.90 & 61.30 & 10.33 & 764.25 & 5.34 & 252.38 & 1.71 & 102.43 \\
Total (7 Days) & $\mathbf{1 6 . 8 0}$ & $\mathbf{5 4 1 . 0 0}$ & $\mathbf{8 3 . 7 9}$ & $\mathbf{4 1 8 6 . 0 0}$ & $\mathbf{3 6 . 9 1}$ & $\mathbf{1 7 4 1 . 5 0}$ & $\mathbf{1 0 . 1 1}$ & $\mathbf{6 3 6 . 7 2}$ \\
Mean per day (over 7 Days) & $\mathbf{2 . 4 0}$ & $\mathbf{7 7 . 2 9}$ & $\mathbf{1 1 . 9 7}$ & $\mathbf{5 9 8 . 0 0}$ & $\mathbf{5 . 2 7}$ & $\mathbf{2 4 8 . 8 8}$ & $\mathbf{1 . 4 4}$ & $\mathbf{9 0 . 9 0}$ \\
\hline
\end{tabular}

*D: Daily walking distance in km; C: Calories burnt. 
Table 4. Health-promoting lifestyle profile (HPLP) among nursing students in Malaysia.

\begin{tabular}{ccccc}
\hline Sub-Scale & Minimum & Maximum & Mean & SD \\
\hline Health Responsibility & 1.22 & 3.44 & 2.26 & 0.45 \\
Physical Activity & 0.88 & 4.38 & 1.74 & 0.39 \\
Nutrition & 1.44 & 3.56 & 2.45 & 0.38 \\
Spiritual Growth & 1.78 & 3.89 & 2.92 & 0.43 \\
Interpersonal Relations & 1.78 & 3.89 & 2.89 & 0.39 \\
Stress Management & 1.38 & 3.75 & 2.60 & 0.42 \\
HPL Total (N = 189) & 1.83 & 3.63 & 2.57 & 0.33 \\
\hline
\end{tabular}

The health-promoting lifestyle profile mean score of $2.58 \pm 0.33$ suggested that student nurses in Malaysia adopted a moderate health-promoting lifestyle. However, the participants were found to have responded differently to the six sub-scales in this study. The highest score was reported for spiritual growth, followed by interpersonal relations and stress management while the lowest score was reported for lifestyle related to physical activity, followed by health responsibility and nutrition.

The relationship between physical activity (as measured using the pedometer) and lifestyle habit (as indicated by responses to the health-promoting lifestyle questionnaire) was investigated using Pearson product-moment correlation coefficient. Preliminary analyses were performed to ensure there was no violation of assumptions of normality, linearity, and homoscedasticity. According to the results as shown in Table 5, there was no correlation [12] between physical activity and overall Health-promoting Lifestyle among the student nurses. However, there is a significant result reported between physical activity (measured using the pedometer) and physical activity habit (measured using the same questionnaire) during weekday, weekend and total 7 days. The reported $\mathrm{r}$ value was $r=0.22, n=189, p<0.01)$ for weekday $(r=0.21, n=189, p<0.01)$ for weekend, and $(r=0.24, n=$ 189, $\mathrm{p}<0.01$ ) for total 7 days step count, respectively. This showed that when the participants indicated that they were physically active, such indications were found to slight correspond to the level real life daily physical activity. However, the relationship found needed to be taken cautiously due to the large sample size.

On the other hand, although the results were not significant, variables such as spiritual growth, health responsibility (during weekend), and stress management and spiritual growth (during weekday) were reported to have negative correlation with physical activity (as measured using the pedometer). This indicated that when student nurses spent more time on spiritual growth $(\mathrm{r}=-0.02, \mathrm{n}=189, \mathrm{p}<0.76)$, health responsibility $(\mathrm{r}=-0.01$, $\mathrm{n}=$ 189, $\mathrm{p}<0.82)$ during the weekend, stress management $(\mathrm{r}=-0.01, \mathrm{n}=189, \mathrm{p}<0.82)$, and spiritual growth $(\mathrm{r}=$ $-0.03, \mathrm{n}=189, \mathrm{p}<0.60)$ during the weekday, their time spent on physical activities will be compromised and reduced.

\section{Discussion and Conclusion}

According to the physical activity standards suggested by Tudor-Locke and Bassett (2004), taking less than 5000 steps per day is considered as “sedentary”, 5000 - 7499 steps per day is considered as "low active”, 7500 9999 steps per day is considered as “somewhat active” and 10,000 and above steps per day is considered as “active”. Hence, as Malaysian student nurses had a mean step count per day of $8275.97 \pm 2210.174$ (mean over 7 days), they can be considered as "somewhat active”. When the same physical activity standard was applied for the activity level during weekend and weekdays, a lower step count was reported during the weekday (8230.46 \pm 2353.97) as compared to the weekend (8389.75 \pm 2689.12$)$.

When student nurses walked during the weekday, it was normally to attend clinical practices or classes, which were conducted in the hospital or normal classroom located in the hospital or in the universities where they were pursuing their studies. Transportation to the teaching hospital was usually provided by their university. Because of this, they might have failed to reach the desired level of physical activity as measured by their step count. Meanwhile, a higher step count during weekend might be attributed to their leisure activities such as shopping and going out with friends. Another possible explanation for the higher level of physical activity at weekends was that most of the student nurses did not have cars and so they had to use some form of public transportation. 
Table 5. Pearson product-moment correlation between measures of physical activity and health-promoting lifestyle (HPL) of student nurses in Malaysia.

\begin{tabular}{ccccccc}
\hline \multirow{2}{*}{ Sub-Scale } & \multicolumn{2}{c}{ Physical Activity (Weekday) } & \multicolumn{2}{c}{ Physical Activity (Weekend) } & \multicolumn{2}{c}{ Physical Activity (Total 7 Days) } \\
\cline { 2 - 7 } & $\mathbf{r}$ & $\mathbf{p}$ & $\mathbf{r}$ & $\mathbf{p}$ & $\mathbf{r}$ & $\mathbf{p}$ \\
\hline Health Responsibility & 0.03 & 0.62 & -0.01 & 0.82 & 0.02 & 0.76 \\
Physical Activity & 0.22 & $0.01^{*}$ & 0.21 & $0.01^{*}$ & 0.24 & $0.01^{*}$ \\
Nutrition & 0.07 & 0.29 & 0.04 & 0.55 & 0.07 & 0.31 \\
Spiritual Growth & -0.03 & 0.60 & -0.02 & 0.76 & -0.03 & 0.62 \\
Interpersonal Relations & 0.05 & 0.41 & 0.01 & 0.80 & 0.05 & 0.48 \\
Stress Management & -0.01 & 0.82 & 0.04 & 0.57 & 0.00 & 0.97 \\
HPL Total & 0.06 & 0.38 & 0.05 & 0.49 & 0.06 & 0.37 \\
\hline
\end{tabular}

"Significant at $\mathrm{p}<0.5$.

This required walking to the bus-stop, for instance. Moreover, weekend activities also included cleaning, washing/laundering, and grocery shopping. Hence, a higher step count was recorded during the weekend. However, considering the total step count for a whole week, it was found that majority of the participants did not achieve the 10,000 step counts per day as suggested by the Ministry of Health, the equivalent of the optimum level of physical activity [13]. A lower physical activity level meant that the nursing students walked shorter distances and burnt lower calories.

If there is no balance between calorie intake and physical activity, the body is programmed to store excess calories as fat or unused energy. Fat accumulation in the body not only impairs movement and flexibility, but also poses greater potential health risk [4] [14]. Furthermore, finding from present study (Table 2) also reveal that some of the students nurses have high body mass index value (more then 25). In general, body mass index is often used as a screening tool to decide if your weight might be putting you at risk for health problems such as heart disease, diabetes, and cancer [15]. Hence, when student nurses are encouraged to have a healthy lifestyle and be physically more active so as to maintain good health, they would more likely to also encourage their patients to do likewise.

The findings of this study showed the opposite of what was reported in a study by Lee [16]. In that study carried out in Taiwan [16] it was found that the energy expenditure of clinical nurses was higher during the weekday than at the weekend. This might be due to the differences in the backgrounds of the participants and their working environment. While the participants in this study were young student nurses who were undergoing training at Malaysian universities, the subjects in the study by Lee [16] comprised older, working clinical nurses in Taipei. These nurses were attached to the hospital Intensive Care Unit (ICU). Usually a clinical ICU nurse was tasked with caring for one critically ill patient in the ICU. The job was very mentally and physically demanding as compared to the clinical work carried out by student nurses. Therefore, it is not surprising that ICU nurses were reported to be more active as compared to student nurses who only attended clinical practice and classes in the classroom. Meanwhile, during the weekend, the ICU nurses perceived laziness and lack of time as the main barriers that restricted their involvement in physical activity whereas, for young student nurses, the weekend was a time to indulge in leisure activities. Since most of the student nurses did not have their own transport, they had to resort to public transportation, which required them to do more walking. That was why student nurses had almost similar mean step count readings for both weekend (8230.46 \pm 2353.97$)$ and weekday (8389.75 \pm 2689.12).

If one maintains a sedentary lifestyle, one's metabolism will slow down. Eventually, joints mobility, muscle strength and endurance will be affected. Findings of previous studies indicate that regular physical activity helps strengthen the heart muscles and also minimises heart diseases, a leading cause of deaths in Malaysia [17] [18]. In addition, it can help to reduce the escalating number of obese Malaysians [19]. According to published statistics, Malaysia was ranked sixth in the Asia-Pacific region for obesity and topped the list in South-East Asia for both obesity and diabetes [20] [21]. It was reported that there were about three million obese Malaysians and the number was increasing. The reported number excluded the five million individuals who suffered from varying 
degrees of diabetes as a result of obesity. This alarming condition was reported to be snowballing in Malaysia because there were more overweight children now as compared to previous years [20] [22]. Hence, the government has labelled obesity as a "disease" in order to increase the awareness of the dangers of the condition. However, this labelling was found to be ineffective because this year (2014), Malaysia was reported to have the highest obesity rate in South-East Asia and the sixth in the Asia-Pacific Region [23] [24]. Findings from the British Medical Journal, The Lancet, showed that $49 \%$ of women and $44 \%$ of men in this country were found to be obese. Malaysia was rated heavyweight at $45.3 \%$ of its population, followed by South Korea (33.2\%), Pakis$\tan (30.7 \%)$ and China (28.3\%). Obesity is a very serious health problem because it will increase the number of patients with diabetes, heart problems, and other diseases [24].

Previous studies have shown that without changing one's diet, a 30-minute brisk walk per day maintained over six days per week is enough to take inches off the waistline and reduce the risk of getting metabolic syndrome [25] [26]. In this study, according to the mean step count reported by the student nurses during the weekday, weekend or for a week in the present study, it can be concluded that student nurses in Malaysia do not walk enough and, therefore, are not able to reap the benefits of walking. Moreover, the estimates of physical activity across the week might be alarmingly lower than what was observed in this study as the pedometer for adolescents and adults often report increased step count per day just by wearing it. This behaviour is called reactivity and is commonly reported especially among female pedometer users [27]-[29]. In other words, it was very likely that Malaysian student nurses did even less walking than was recorded by the pedometer. However, the use of a sealed pedometer and daily log in this study, as suggested by Clemes [28], might have minimised the reactivity effect.

With regard to the second objective of the study, viz. to determine the health-promoting lifestyle of nursing students in Malaysia, the findings in this study indicated that there was some engagement in a moderate health-promoting lifestyle, with its mean at $2.58 \pm 0.33$. However, it was somewhat surprising that the participants responded differently to all the six sub-scale measures in this study. The highest score was reported for spiritual growth (mean $=2.92$ ), followed by interpersonal relations (mean $=2.98)$, and stress management (mean $=2.60$ ) while the lowest score was reported for lifestyle related to physical activity (mean $=1.74$ ), followed by health responsibility (mean $=2.26$ ), and nutrition (mean $=2.45$ ). These findings indicated that student nurses in Malaysia were very religious and placed a lot of emphasis on spiritual growth. A similar result (mean $=2.98)$ was also reported among Jordanian student nurses, the majority (more then 90\%) of whom were Muslim. The results of previous studies confirm the view that the existence of a relationship between religious instructions and physical activity affects behavior [30]-[32]. It was also noteworthy that the result for physical activity as measured by the questionnaire was found to be in line with the physical activity result reported by the pedometer. Both sets of results showed that there was a slight positive correlation between these two variables. When the student nurses indicated in the questionnaire that they were not active, their lack of activity was also reflected by a lower step count using the pedometer.

The findings of this of this study concurred with those of a study conducted in Hong Kong [33] where relatively few universities students (27.1\%) had a sense of health responsibility. Most of the students (31.2\%) were also reported not to be engaged in any form of physical activity, nor did they exercise regularly (13.8\%). Similar results were also reported in a study [34] where Canadian and Jordanian student nurses ranked health responsibility the lowest in the sub-scales. Besides, it was also highlighted [33] that male subjects scored better in the physical exercise sub-scale as compared to their female counterparts $(\mathrm{p}=0.01)$. This finding was found to be in line with many studies which reported that males were usually more active physically [35]-[37]. All these findings strengthen and confirm the need to promote more exercise programs especially among female students, taking into account gender differences and specific needs. As mentioned earlier, the lifestyle embraced by student nurses is very important in determining their health promotion action when dealing with patients after their graduation. If they were convinced of the need to adopt a healthy lifestyle, with adequate physical exercise and a proper diet, the task of encouraging their patients to do likewise would be much easier. As indicated by McDowell and Al-Kandari [38] [39], activity promotion and personal behaviour of health care professionals are associated with the promotion of healthcare for patients. Hence, with their health-promoting lifestyle and knowledge, student nurses would be able to perform their role more effectively as practitioners. According to Lobelo [6], they have a moral responsibility to prescribe physical activity to patients under their supervision in order to improve their health. 


\section{Conclusion}

The prevalence of health problems like obesity and type II diabetes is normally associated with the lack of physical activity [19] [20]. Therefore, there is an urgent need to incorporate exercise as a vital element in any health promotion campaign. Nurses as health professionals play an important role in health promotion. The current study was aimed at determining the physical activity level and health-promoting lifestyle among student nurses in Malaysia and also to investigate whether there was a correlation between the physical activity levels with the lifestyle habit among nursing students. The findings from this study showed that their level of physical activity was lower than optimum, thus highlighting the need to encourage student nurses to be more active. According to a study [5] [6], the lack of regular physical exercise among the nurses is a concern as it is related to lower competence to prescribe adequate preventive physical exercise recommendations to their patients in the future. This descriptive study identified key correlates of physical activity and found that the relationships between the sub-scales of health-promoting lifestyle and physical activity was insignificant except in the case of students' report of their physical activity. With the current attention directed to the problem of lack of physical activity among Malaysians in general, future studies may design, evaluate, and emphasize the effect of interventions to increase the level of physical activity. The intervention of educators and parents could also be a focus of future studies as the importance of a healthy lifestyle is best imprinted on young minds. These new generations of youth, including nursing students, are tech savvy and spend a large proportion of their time surfing on the Internet, networking via smart phones, playing computer games and toying with electronic gadgets. As youth become more sedentary in their lifestyle, it is crucial to put in place appropriate interventions to ensure that they learn the importance of exercises and a healthy lifestyle. Student nurses should be role models in the adoption of a healthy lifestyle so that they can be a source of encouragement to their patients and members of their community.

\section{Acknowledgements}

This study was funded by University Putra Malaysia Research University Grant (Project No: 06-05-10-1112RU). The authors would like to express special thanks to the universities that involved in this study and the subjects for their cooperation.

\section{References}

[1] Anonymous (2009) Two in Five Adults Overweight or Obese in Malaysia. In: The Star, The Star, Selangor.

[2] Irazusta, A., Gil, S., Ruiz, F., Gondra, J., Jauregi, A., Irazusta, J. and Gil, J. (2006) Exercise, Physical Fitness, and Dietary Habits of First-Year Female Nursing Students. Biological Research for Nursing, 7, 175-186. http://dx.doi.org/10.1177/1099800405282728

[3] Astrup, A. (2001) Healthy Lifestyles in Europe: Prevention of Obesity and Type II Diabetes by Diet and Physical Activity. Public Health Nutrition, 4, 499-515. http://dx.doi.org/10.1079/PHN2001136

[4] Hossain, P., Kawar, B. and El Nahas, M. (2007) Obesity and Diabetes in the Developing World—A Growing Challenge. New England Journal of Medicine, 356, 213-215. http://dx.doi.org/10.1056/NEJMp068177

[5] Burns, K.J., Camaione, D.N. and Chatterton, C.T. (2000) Prescription of Physical Activity by Adult Nurse Practitioners: A National Survey. Nursing Outlook, 48, 28-33. http://dx.doi.org/10.1067/mno.2000.99101

[6] Lobelo, F., Duperly, J. and Frank, E. (2009) Physical Activity Habits of Doctors and Medical Students Influence Their Counselling Practices. British Journal of Sports Medicine, 43, 89-92. http://dx.doi.org/10.1136/bjsm.2008.055426

[7] Bassett Jr., D.R., Ainsworth, B.E., Leggett, S.R., Mathien, C.A., Main, J.A., Hunter, D.C. and Duncan, G.E. (1996) Accuracy of Five Electronic Pedometers for Measuring Distance Walked. Medicine and Science in Sports and Exercise, 28, 1071-1077. http://dx.doi.org/10.1097/00005768-199608000-00019

[8] Bassett Jr., D.R., Cureton, A.L. and Ainsworth, B.E. (2000) Measurement of Daily Walking Distance-Questionnaire versus Pedometer. Medicine and Science in Sports and Exercise, 32, 1018-1023. http://dx.doi.org/10.1097/00005768-200005000-00021

[9] Tudor-Locke, C., Burkett, L., Reis, J.P., Ainsworth, B.E., Macera, C.A. and Wilson, D.K. (2005) How Many Days of Pedometer Monitoring Predict Weekly Physical Activity in Adults? Preventive Medicine, 40, 293-298. http://dx.doi.org/10.1016/j.ypmed.2004.06.003

[10] Rowlands, A.V., Stone, M.R. and Eston, R.G. (2007) Influence of Speed and Step Frequency during Walking and Running on Motion Sensor Output. Medicine and Science in Sports and Exercise, 39, 716-727. 
http://dx.doi.org/10.1249/mss.0b013e318031126c

[11] Walker, S.N., Sechrist, K.R. and Pender, N.J. (1987) The Health-Promoting Lifestyle Profile: Development and Psychometric Characteristics. Nursing Research, 36, 76-81. http://dx.doi.org/10.1097/00006199-198703000-00002

[12] Cohen, J. (1988) Set Correlation and Contingency Tables. Applied Psychological Measurement, 12, 425-434. http://dx.doi.org/10.1177/014662168801200410

[13] Anonymous (2009) 10,000 Steps a Day Campaign to Improve Health. In: The Star, Selangor.

[14] Eisenmann, J.C., Wickel, E.E., Welk, G.J. and Blair, S.N. (2005) Relationship between Adolescent Fitness and Fatness and Cardiovascular Disease Risk Factors in Adulthood: The Aerobics Center Longitudinal Study (acls). American Heart Journal, 149, 46-53. http://dx.doi.org/10.1016/j.ahj.2004.07.016

[15] Anonymous (2013) Normal Weight Ranges: Body Mass Index (BMI). http://www.cancer.org/cancer/cancercauses/dietandphysicalactivity/bodyweightandcancerrisk/body-weight-and-cancerrisk-adult-bmi

[16] Lee, Y.S., Huang, Y.C. and Kao, Y.H. (2005) Physical Activities and Correlates of Clinical Nurses in Taipei Municipal Hospitals. Journal of Nursing Research, 13, 281-292. http://dx.doi.org/10.1097/01.JNR.0000387551.50458.f5

[17] Khoo, K.L., Tan, H. and Khoo, T.H. (1991) Cardiovascular Mortality in Peninsular Malaysia: 1950-1989. Medical Journal Malaysia, 46, 7-20.

[18] Robaayah, Z. (2004) Trends in Cardiovascular Diseases and Risk Factors in Malaysia. In: International Congress Series, Elsevier, 446-449.

[19] Ismail, M.N., Chee, S.S., Nawawi, H., Yusoff, K., Lim, T.O. and James, W.P.T. (2002) Obesity in Malaysia. Obesity Reviews, 3, 203-208. http://dx.doi.org/10.1046/j.1467-789X.2002.00074.x

[20] Edwards, A.R.F. (2013) Obesity a Big Problem Now in Malaysia. http://www.thestar.com.my/news/nation/2013/11/17/obesity-a-big-problem-now-about-three-million-malaysians-are-o bese-says-deputy-minister/

[21] Patrick, L. (2014) Malaysia Is Fattest Country in South-East Asia. http://www.thestar.com.my/News/Nation/2014/01/16/Scoring-badly-on-dietary-habits-Malaysia-is-fattest-country-in-S E-Asia/

[22] Adeyemi, A.J., Rohani, J.M. and Abdul Rani, M.R. (2014) Comparing Body Composition Measures among Malaysian Primary School Children. Cogent Medicine, 1, 1-12. http://dx.doi.org/10.1080/2331205X.2014.984385

[23] Anonymous (2014) Malaysia’s Obesity Rate Highest in Asia. In: The Star, Selangor.

[24] Anonymous (2014) Malaysia BJJ, Health \& Exercise: Why Are We Still Overweight? http://goodhealthwithbjj.blogspot.com/2014/08/why-are-we-still-overweight.html

[25] Stan Reents, P. (2014) Health Benefits of Walking. http://www.athleteinme.com/ArticleView.aspx?id=296

[26] Wannamethee, S.G., Shaper, A.G. and Walker, M. (1998) Changes in Physical Activity, Mortality, and Incidence of Coronary Heart Disease in Older Men. The Lancet, 351, 1603-1608. http://dx.doi.org/10.1016/S0140-6736(97)12355-8

[27] Bravata, D.M., Smith-Spangler, C., Sundaram, V., Gienger, A.L., Lin, N., Lewis, R., Stave, C.D., Olkin, I. and Sirard, J.R. (2007) Using Pedometers to Increase Physical Activity and Improve Health: A Systematic Review. The Journal of the American Medical Association, 298, 2296-2304. http://dx.doi.org/10.1001/jama.298.19.2296

[28] Clemes, S. and Parker, R. (2009) Increasing Our Understanding of Reactivity to Pedometers in Adults. Medicine and Science in Sports and Exercise, 41, 674. http://dx.doi.org/10.1249/MSS.0b013e31818cae32

[29] Ho, V., Simmons, R.K., Ridgway, C.L., Van Sluijs, E.M.F., Bamber, D.J., Goodyer, I.M., Dunn, V.J., Ekelund, U. and Corder, K. (2013) Is Wearing a Pedometer Associated with Higher Physical Activity among Adolescents? Preventive Medicine, 56, 273-277. http://dx.doi.org/10.1016/j.ypmed.2013.01.015

[30] Benjamins, M.R. (2012) Religious Beliefs, Diet, and Physical Activity among Jewish Adolescents. Journal for the Scientific Study of Religion, 51, 588-597. http://dx.doi.org/10.1111/j.1468-5906.2012.01658.x

[31] Kim, K.H.-C. and Sobal, J. (2004) Religion, Social Support, Fat Intake and Physical Activity. Public Health Nutrition, 7, 773-781. http://dx.doi.org/10.1079/PHN2004601

[32] Wallace, J.M. and Forman, T.A. (1998) Religion’s Role in Promoting Health and Reducing Risk among American Youth. Health Education \& Behavior, 25, 721-741. http://dx.doi.org/10.1177/109019819802500604

[33] Lee, R.L.T. and Loke, A.J.T. (2005) Health Promoting Behaviors and Psychosocial Well Being of University Students in Hong Kong. Public Health Nursing, 22, 209-220. http://dx.doi.org/10.1111/j.0737-1209.2005.220304.x

[34] Haddad, L., Kane, D., Rajacich, D., Cameron, S. and Al-Ma’aitah, R. (2004) A Comparison of Health Practices of Canadian and Jordanian Nursing Students. Public Health Nursing, 21, 85-90.

http://dx.doi.org/10.1111/j.1525-1446.2004.21112.x 
[35] Caspersen, C.J., Pereira, M.A. and Curran, K.M. (2000) Changes in Physical Activity Patterns in the United States, by Sex and Cross-Sectional Age. Medicine and Science in Sports and Exercise, 32, 1601-1609. http://dx.doi.org/10.1097/00005768-200009000-00013

[36] Crespo, C.J., Keteyian, S.J., Heath, G.W. and Sempos, C.T. (1996) Leisure-Time Physical Activity among US Adults: Results from the Third National Health and Nutrition Examination Survey. Archives of Internal Medicine, 156, 93-98. http://dx.doi.org/10.1001/archinte.1996.00440010113015

[37] Pratt, M., Macera, C.A. and Blanton, C. (1999) Levels of Physical Activity and Inactivity in Children and Adults in the United States: Current Evidence and Research Issues. Medicine and Science in Sports and Exercise, 31, S526-S533. http://dx.doi.org/10.1097/00005768-199911001-00007

[38] Al-Kandari, F. and Vidal, V.L. (2007) Correlation of the Health-Promoting Lifestyle, Enrollment Level, and Academic Performance of College of Nursing Students in Kuwait. Nursing \& Health Sciences, 9, 112-119. http://dx.doi.org/10.1111/j.1442-2018.2007.00311.x

[39] Mcdowell, N., Mckenna, J. and Naylor, P.J. (1997) Factors That Influence Practice Nurses to Promote Physical Activity. British Journal of Sports Medicine, 31, 308-313. http://dx.doi.org/10.1136/bjsm.31.4.308 